\title{
Moderate alcohol intake and markers of inflammation and endothelial dysfunction among diabetic men
}

\author{
I. Shai ${ }^{1,2,3}$ • E. B. Rimm ${ }^{1,2,4}$ - M. B. Schulze ${ }^{1}$ N. Rifai ${ }^{5}$ M. J. Stampfer ${ }^{1,2,4}$ • F. B. Hu Hu $^{1,2,4}$ \\ ${ }^{1}$ Department of Nutrition, Harvard School of Public Health, Boston, Massachusetts, USA \\ 2 Department of Epidemiology, Harvard School of Public Health, Boston, USA \\ ${ }^{3}$ Department of Epidemiology, S. Daniel Abraham International Center for Health and Nutrition, \\ Ben-Gurion University of the Negev, Beer-Sheva, Israel \\ ${ }^{4}$ Channing Laboratory, Department of Medicine, Brigham and Women's Hospital and Harvard Medical School, \\ Boston, Massachusetts, USA \\ ${ }^{5}$ Department of Laboratory Medicine, Children's Hospital and Harvard Medical School, Boston, Massachusetts, USA
}

\section{Abstract}

Aims/hypothesis. Type 2 diabetes mellitus is characterised by heightened inflammation and endothelial dysfunction. Moderate alcohol intake has been associated with a reduced risk of cardiovascular disease in Type 2 diabetic patients. It remains to be determined whether there is an association between alcohol and inflammation in individuals with diabetes.

Methods. We investigated the relationship between alcohol intake and inflammation in 726 of 18,159 men who returned blood samples in the Health Professionals Follow-up Study and had confirmed Type 2 diabetes at blood draw.

Results. In age-adjusted analyses, alcohol intake was associated with lower levels of $\mathrm{HbA}_{1} \mathrm{c}$, fibrinogen, soluble tumour necrosis factor receptor-2 (sTNF-R2) and soluble vascular adhesion molecule-1 (sVCAM-1), and with higher levels of HDL cholesterol and ad- iponectin ( $p$ value for trends $<0.05$ ). After adjustment for age, $\mathrm{HbA}_{1} \mathrm{c}$, insulin use, fasting status, smoking, BMI, physical activity, aspirin use, prevalence of cardiovascular disease and dietary factors, each additional drink per day was related to increased HDL cholesterol $(0.053 \mathrm{mmol} / \mathrm{l}, p<0.0001)$ and adiponectin $(0.8 \mu \mathrm{g} / \mathrm{ml}, p=0.01)$, and decreased sTNFR-2 $(73 \mathrm{pg} / \mathrm{ml}$, $p=0.03)$, fibrinogen $(0.302 \mu \mathrm{mol} / 1, \quad p=0.02)$ and sVCAM-1 (33 ng/ml, $p=0.02)$. The relationship between alcohol and inflammatory biomarkers persisted when subjects were stratified according to $\mathrm{HbA}_{1} \mathrm{c}$ levels.

Conclusions/interpretation. Moderate alcohol intake may have a beneficial effect on markers of inflammation and endothelial dysfunction in Type 2 diabetic patients.

Keywords Alcohol · Cardiovascular disease . Diabetes mellitus · Inflammation
Received: 26 February 2004 / Accepted: 25 May 2004

Published online: 22 October 2004

(C) Springer-Verlag 2004

\section{Shai $(\bowtie)$}

Department of Epidemiology, Harvard School of Public Health, 677 Huntington Avenue, Boston, MA 02115, USA

E-mail: ishai@hsph.harvard.edu

Tel.: +1-617-4326315, Fax: +1-617-5667805

Abbreviations: apoB ${ }_{100}$, apolipoprotein $\mathrm{B}_{100} \cdot \mathrm{CRP}, \mathrm{C}$-reactive protein - CVD, cardiovascular disease $\cdot$ HPFS, Health Professionals Follow-up Study · Lp(a), Lipoprotein (a) · MET, metabolic equivalent task per week · sICAM-1, soluble intercellular adhesion molecule-1 - sTNF-R2, soluble tumour necrosis factor receptor- $2 \cdot \mathrm{sVCAM}-1$, soluble vascular adhesion molecule-1

\section{Introduction}

Type 2 diabetes mellitus appears to have a strong inflammatory component [1]. Plasma levels of C-reactive protein (CRP) [1], interleukin-6 (IL-6) $[1,2]$, TNF- $\alpha$ [2], fibrinogen [3], soluble cell adhesion molecules [4] and other systemic markers of inflammation [5] have been found to be significantly elevated in patients with Type 2 diabetes. Adiponectin, which has insulinsensitising [6] and anti-inflammatory [7] properties, has been reported to be independently associated with a reduced risk of Type 2 diabetes [8]. These findings suggest a potential link between insulin resistance and markers of inflammation and endothelial dysfunction.

Moderate alcohol consumption has been associated with a reduced risk of cardiovascular disease (CVD) 
[9] and Type 2 diabetes [10]. Moderate alcohol consumption has been linked to reduced cardiovascular risk in Type 2 diabetic patients [11, 12, 13, 14, 15]; this beneficial effect is greater in diabetic individuals than in non-diabetic individuals [14], producing a $34 \%$ to $79 \%$ reduction in the risk of CHD [15]. Investigations into the mechanisms responsible for this association have focused primarily on lipid metabolism [16], coagulation, fibrinolysis [17] and insulin sensitivity [18]. However, the pathways by which alcohol influences the cardiovascular system are not entirely clear.

Moderate alcohol consumption was recently found to be associated with reduced levels of inflammatory biomarkers $[19,20]$ and with improved endothelial function [21, 22]. However, no previous study has examined the associations between alcohol intake and plasma markers of inflammation and endothelial dysfunction in diabetic patients. The aim of the present study was to examine these relationships in diabetic men enrolled in the Health Professionals Follow-up Study (HPFS).

\section{Subjects and methods}

Population and diabetes definition. The HPFS is a prospective cohort study of 51,529 US male health professionals who were aged between 40 and 75 years at study initiation in 1986. The cohort is followed using biennial mailed questionnaires that focus on various lifestyle factors and health outcomes. Between 1993 and 1994, 18,159 study participants provided blood samples by overnight courier. Of the participants who returned blood samples, 730 had a confirmed diagnosis of Type 2 diabetes (as reported on a supplementary questionnaire sent to all men who reported a diagnosis of diabetes). Confirmation of diabetes required at least one of the following [23]: (i) fasting plasma glucose $\geq 7.8 \mathrm{mmol} / 1$, random plasma glucose $\geq 11.1 \mathrm{mmol} / 1$ and/or plasma glucose $\geq 11.1 \mathrm{mmol} / \mathrm{l}$ after $\geq 2 \mathrm{~h}$ during an OGTT plus at least one classic symptom (excessive thirst, polyuria, weight loss or hunger); (ii) no symptoms, but at least two elevated plasma glucose concentrations (by the above criteria) on different occasions; or (iii) treatment with hypoglycaemic medication. The validity of self-reported diabetes using the supplementary questionnaire was confirmed in $97 \%$ of cases [24]. The participants provided written informed consent to be included in the study and all investigations were approved by the institutional review board ethics committee.

Assessment of diet and alcohol. Average nutrient intake was derived from the validated semiquantitative food frequency questionnaire administered in 1994 [25]. Standard portion sizes for alcoholic drinks were specified as a can/bottle or glass for beer, a glass of wine containing $11 \mathrm{~g}$ alcohol and one drink or shot for liquor. In a validation study within the HPFS, the correlation between the alcohol intakes reported in the food frequency questionnaire and the average of two 1-week diet records was 0.86 [26].

Blood collection. Each interested participant was sent a blood collection kit containing instructions and needle supplies. Blood samples were collected in three 10-ml liquid EDTA blood tubes, placed on ice packs stored in styrofoam containers and returned to our laboratory via overnight courier; over $95 \%$ of the samples arrived within $24 \mathrm{~h}$. After receipt, the chilled blood was centrifuged, aliquotted into plasma, erythrocytes and buffy coat, and stored in continuously monitored nitrogen freezers at temperatures no higher than $-130{ }^{\circ} \mathrm{C}$. We requested information on the date and time of the blood sample drawing and the time elapsed since the preceding meal to identify nonfasting ( $>8 \mathrm{~h}$ ) subjects.

Laboratory methods. All assays were performed in the laboratory of N. Rifai, which is certified by the National Heart, Lung and Blood Institute/Centers for Disease Control and Prevention Lipid Standardization Program. All the methods except the ELISA and RIA used the Hitachi 911 analyzer (Roche Diagnostics, Indianapolis, Ind., USA). Measurement of $\mathrm{HbA}_{1} \mathrm{c}$ was based on turbidimetric immunoinhibition using haemolysed packed red cells. The intra-assay $\mathrm{CV}$ of measurements of percent $\mathrm{HbA}_{1} \mathrm{c}$ was $<3.0 \%$. Levels of soluble TNF receptor- 2 (sTNF-R2), soluble intercellular adhesion molecule-1 (sICAM-1) and soluble vascular adhesion molecule-1 (sVCAM-1) were measured using ELISA kits from R\&D systems (Minneapolis, Minn., USA) with mean CVs of 4.1, 7.4 and 9.2\% respectively. The sTNF receptors are produced by the proteolytic cleavage of TNF cell surface receptors following induction by TNF or other cytokines such as IL-6, IL-1 $\beta$ or IL-2. They have a longer half-life than TNF and are detected with a higher sensitivity [27]. Similarly, the soluble adhesion molecules are derived from the proteolytic cleavage of the ectodomain of the adhesion molecules. Levels of high-sensitivity CRP and fibrinogen were measured using immunoturbidimetric assays with CVs of 1.8 and $1.2 \%$ respectively. Adiponectin was measured by a RIA from Linco Research (St Louis, Mo., USA) with a CV of $<9.3 \%$.

Concentrations of total cholesterol, triglycerides and HDL cholesterol were analysed simultaneously using enzymatic assays with CVs of $1.7,1.8$ and $2.5 \%$ respectively. Levels of LDL cholesterol was determined by a homogenous direct method (Genzyme, Cambridge, Mass., USA) with a CV of $<3.1 \%$. Apolipoprotein $\mathrm{B}_{100}\left(\mathrm{apoB}_{100}\right)$ was measured by an immunoturbidimetric technique (Roche Diagnostics) with a $\mathrm{CV}$ of $4.3 \%$. Lipoprotein a (Lp[a]) was assessed by a latexenhanced immunoturbidimeteric method (Denka Sieken, Tokyo, Japan) with a CV of $2.6 \%$.

Data analysis. After excluding two men with missing alcohol intake data and two men who consumed above $70 \mathrm{~g}$ of alcohol per day (above the 98th percentile), 726 men with prevalent Type 2 diabetes remained in the analyses. The men were divided into five categories of alcohol intake: non-drinkers, 0.1-4.9, 5-14.9, 15-24.9 and 25-70 g/day. The glycaemic index of the diet was calculated by using glycaemic index values for individual foods. The glycaemic load was calculated by multiplying the grams of carbohydrate in each serving by its glycaemic index value. Each unit of dietary glycaemic load represents the equivalent of $1 \mathrm{~g}$ of carbohydrate from pure glucose.

We used general linear models to determine the geometric mean levels and percentages of the population characteristics and plasma biomarker levels across the alcohol groups. The $p$ value for trend was assessed by the weighted regression of the median value of each of the alcohol groups. We used linear regression models to assess the parameter estimates ( $\beta$ coefficients) for an increment in alcohol intake of $12.5 \mathrm{~g} /$ day (average portion size). In multivariable models we controlled for age, $\mathrm{HbA}_{1} \mathrm{c}$ (quintiles), insulin use, fasting status (less or more than $8 \mathrm{~h}$ ), smoking (current, past, never), BMI (continuous), physical activity (metabolic equivalent task per week [MET], 
Table 1. Age-adjusted characteristics of 726 diabetic men across categories of alcohol intake

\begin{tabular}{|c|c|c|c|c|c|c|}
\hline \multirow[t]{2}{*}{ Characteristic } & \multicolumn{5}{|c|}{ Alcohol intake (g/day), (median) } & \multirow{2}{*}{$\begin{array}{l}p \text { value } \\
\text { for trend }\end{array}$} \\
\hline & 0 & $\begin{array}{l}0.1-4.9 \\
(2.0)\end{array}$ & $\begin{array}{l}5-14.9 \\
(9.3)\end{array}$ & $\begin{array}{l}15-24.9 \\
(18.6)\end{array}$ & $\begin{array}{l}25-70 \\
(37.7)\end{array}$ & \\
\hline Number of subjects & 259 & 168 & 152 & 63 & 84 & \\
\hline Age (years) & 67 & 65 & 66 & 66 & 66 & 0.43 \\
\hline Current smokers ${ }^{a}$ & 4 & 4 & 8 & 8 & 8 & 0.0001 \\
\hline History of hypertension ${ }^{a}$ & 53 & 54 & 53 & 45 & 56 & 0.96 \\
\hline History of hypercholesterolaemia ${ }^{a}$ & 51 & 51 & 55 & 52 & 60 & 0.16 \\
\hline Prevalence of CVD ${ }^{a}, c$ & 16 & 16 & 21 & 14 & 20 & 0.32 \\
\hline Parental MI before 60 years $^{\mathrm{a}}$ & 13 & 14 & 12 & 14 & 13 & 0.98 \\
\hline Insulin use & 33 & 21 & 27 & 28 & 21 & 0.08 \\
\hline Aspirin use $>5$ days/week ${ }^{\mathrm{a}}$ & 32 & 44 & 45 & 53 & 48 & 0.01 \\
\hline Energy (kcal) & 2024 & 1976 & 2062 & 2003 & 1949 & 0.50 \\
\hline Carbohydrate (\% of energy) & 49.8 & 49.3 & 48.2 & 47.6 & 47.6 & 0.01 \\
\hline Protein ( $\%$ of energy) & 19.3 & 19.5 & 19.1 & 19.1 & 18.7 & 0.07 \\
\hline Total fat (\% of energy) & 30.9 & 31.2 & 32.8 & 33.4 & 33.7 & 0.01 \\
\hline Saturated fats ( $\%$ of energy) & 10.1 & 10.4 & 10.7 & 10.9 & 11.1 & 0.01 \\
\hline Monounsaturated fats ( $\%$ of energy) & 12.1 & 12.2 & 13.0 & 13.4 & 13.8 & $<0.0001$ \\
\hline Polyunsaturated fats ( $\%$ of energy) & 5.7 & 5.5 & 6.0 & 5.9 & 5.8 & 0.22 \\
\hline Trans fat (\% of energy) & 2.8 & 2.9 & 3.1 & 3.1 & 3.2 & 0.06 \\
\hline Total omega 3 fatty acids ( $\%$ of energy $)^{\mathrm{d}}$ & 1.5 & 1.5 & 1.5 & 1.5 & 1.4 & 0.75 \\
\hline Glycaemic load & 134.7 & 130.8 & 123.7 & 119.5 & 108.4 & $<0.0001$ \\
\hline Glycaemic index & 52.9 & 52.4 & 51.8 & 52.2 & 51.3 & 0.01 \\
\hline
\end{tabular}

Values are geometric means unless otherwise stated. ${ }^{\text {a Values }}$ are percentages; ${ }^{b}$ calculated as hours of activity times its typical energy expenditure; ${ }^{c}$ prevalence of myocardial infarction,

quintiles), aspirin use and prevalence of CVD. We further controlled for dietary score [28], which is the sum of the quintile values of cereal fibre and the ratio of polyunsaturated : saturated fats in ascending order, and trans fats and glycaemic load in descending order. We repeated our regression analysis including alcohol source as three continuous variables, which were computed as follows: $12-\mathrm{oz}$ can of beer $=12.8 \mathrm{~g}$ alcohol, $4-\mathrm{oz}$ glass of wine $=11 \mathrm{~g}$ alcohol and one drink of spirits $=14 \mathrm{~g}$ of alcohol [29]. A $p$ value of less than 0.05 was considered significant. All statistical analyses were performed with SAS statistical software (Version 8.0; SAS Institute, Cary, N.C., USA).

\section{Results}

The study participants predominantly had a light-tomoderate intake of alcohol. In 1994, 259 (36\%) participants abstained from alcohol. The median alcohol intake was $3.4 \mathrm{~g} /$ day in 1986 and dropped to $2.8 \mathrm{~g} /$ day in 1990 and in 1994.

The baseline characteristics of the men are shown in Table 1. Diabetic men who drank more alcohol were more likely to smoke and to use aspirin and cholesterol-lowering medications, and were less likely to use insulin. Alcohol intake was related to higher fat and lower carbohydrate intake, dietary glycaemic load and glycaemic index. angina pectoris, coronary artery bypass grafting or stroke; ${ }^{\mathrm{d}}$ including alpha-linolenic acid and fish oil. MI, myocardial infarction

Table 2 shows age-adjusted mean levels of biomarkers across the alcohol categories. Alcohol intake was associated with lower levels of $\mathrm{HbA}_{1} \mathrm{c}$, sTNFR-2, fibrinogen and SVCAM-1, and higher levels of HDL cholesterol and adiponectin. Increased levels of total cholesterol were mostly driven by HDL cholesterol. There were no significant differences in triglycerides, CRP or sICAM-1 levels across the alcohol groups.

When modelled as a continuous variable, an increment of one drink per day (Table 3) was related to an increase in HDL cholesterol $(0.053 \mathrm{mmol} / \mathrm{l},+5 \%$ as compared to the mean levels of the abstainers) and adiponectin $(0.8 \mu \mathrm{g} / \mathrm{ml},+6 \%)$, and a decrease in sTNFR-2 $(70 \mathrm{pg} / \mathrm{ml},-2 \%)$, fibrinogen $(0.302 \mu \mathrm{mol} / \mathrm{l}$, $-2 \%$ ) and sVCAM-1 levels $(33 \mathrm{ng} / \mathrm{ml},-2 \%)$. The $\beta$ coefficients did not change substantially in multivariable models or after additional adjustment for aspirin use, dietary score or triglycerides. Further adjustment for HDL cholesterol substantially attenuated the relationship between alcohol and adiponectin $(\beta=1.99$, $p=0.47$ ).

To investigate whether levels of glycaemic control modified the association of alcohol with inflammatory biomarkers we divided the men into two groups according to their $\mathrm{HbA}_{1} \mathrm{c}$ levels, applying a cut-off value 
Table 2. Age-adjusted, log-transformed plasma biomarker levels according to level of alcohol intake in 726 diabetic men

\begin{tabular}{|c|c|c|c|c|c|c|}
\hline \multirow[t]{2}{*}{ Characteristic } & \multicolumn{5}{|c|}{ Alcohol intake (g/day) (median) } & \multirow{2}{*}{$\begin{array}{l}p \text { value } \\
\text { for treno }\end{array}$} \\
\hline & 0 & $0.1-4.9(2.0)$ & $5-14.9(9.3)$ & $15-24.9(18.6)$ & $25-70(37.7)$ & \\
\hline $\mathrm{HbA}_{1} \mathrm{c}(\%)$ & 7.5 & 7.2 & 7.2 & 7.4 & 7.1 & 0.04 \\
\hline Triglycerides $(\mathrm{mmol} / \mathrm{l})^{\mathrm{a}}$ & 1.66 & 1.79 & 1.71 & 1.65 & 1.64 & 0.61 \\
\hline Total cholesterol (mmol/) & 5.33 & 5.19 & 5.28 & 5.59 & 5.55 & 0.01 \\
\hline $\mathrm{Lp}(\mathrm{a})(\mu \mathrm{mol} / \mathrm{l})$ & 0.34 & 0.32 & 0.34 & 0.35 & 0.30 & 0.65 \\
\hline $\operatorname{ApoB}_{100}(\mathrm{~g} / \mathrm{l})$ & 1.00 & 1.00 & 1.00 & 1.03 & 1.05 & 0.20 \\
\hline CRP $(\mathrm{mg} / \mathrm{l})$ & 1.7 & 1.9 & 1.9 & 1.9 & 1.5 & 0.43 \\
\hline sTNFR-2 (pg/ml) & 2990.2 & 2964.9 & 2921.9 & 2817.0 & 2792.0 & 0.03 \\
\hline Fibrinogen $(\mu \mathrm{mol} / \mathrm{l})$ & 13.96 & 13.72 & 13.19 & 13.78 & 13.01 & 0.04 \\
\hline sICAM-1 (ng/ml) & 340.4 & 349.1 & 351.8 & 339.4 & 341.6 & 0.85 \\
\hline
\end{tabular}

Values are geometric means unless stated otherwise. a Values only available for subjects who fasted before blood draw ( $n=384)$

Table 3. Parameter estimates of plasma biomarkers for an increment in alcohol intake of 12.5 g/day (equivalent to one drink per day) in 726 diabetic men

\begin{tabular}{lccc}
\hline Biomarker & $\begin{array}{l}\text { Age-adjusted model } \beta_{1} \\
(p \text { value })\end{array}$ & $\begin{array}{l}\text { Multivariable-adjusted } \\
\text { model }^{\mathrm{a}} \beta_{2}(p \text { value })\end{array}$ & $\begin{array}{c}\text { Multivariable and dietary } \\
\text { intake-adjusted model } \\
\beta_{3}(p \text { value })\end{array}$ \\
\hline Triglycerides $^{\mathrm{c}}(\mathrm{mmol} / \mathrm{l})$ & $-0.05(0.32)$ & $-0.05(0.29)$ & $-0.05(0.30)$ \\
Total cholesterol $(\mathrm{mmol} / \mathrm{l})$ & $0.008(0.02)$ & $0.009(0.01)$ & $0.009(0.01)$ \\
LDL cholesterol $(\mathrm{mmol} / \mathrm{l})$ & $0.050(0.15)$ & $0.053(0.11)$ & $0.053(0.11)$ \\
HDL cholesterol $(\mathrm{mmol} / \mathrm{l})$ & $0.005(<0.0001)$ & $0.005(<0.0001)$ & $0.005(<0.0001)$ \\
Lp $(\mathrm{a})(\mu \mathrm{mol} / \mathrm{l})$ & $-0.010(0.75)$ & $-0.015(0.63)$ & $-0.015(0.62)$ \\
ApoB $100(\mathrm{~g} / \mathrm{l})$ & $0.012(0.15)$ & $-0.1(0.48)$ & $0.013(0.10)$ \\
CRP $(\mathrm{mg} / \mathrm{l})$ & $-0.1(0.59)$ & $-73.73(0.03)$ & $-0.1(0.49)$ \\
sTNFR-2 $(\mathrm{pg} / \mathrm{ml})$ & $-61.78(0.06)$ & $-0.303(0.02)$ & $-72.88(0.03)$ \\
Fibrinogen $(\mu \mathrm{mol} / \mathrm{l})$ & $-0.286(0.01)$ & $-0.21(0.94)$ & $-0.302(0.02)$ \\
sICAM-1 $(\mathrm{ng} / \mathrm{ml})$ & $1.31(0.70)$ & $-33.10(0.02)$ & $-0.14(0.96)$ \\
sVCAM-1 $(\mathrm{ng} / \mathrm{ml})$ & $-32.90(0.02)$ & $0.8(0.01)$ & $-32.93(0.02)$ \\
Adiponectin $(\mu \mathrm{g} / \mathrm{ml})$ & $0.8(0.01)$ & $0.8(0.01)$
\end{tabular}

a Adjusted for age, $\mathrm{HbA}_{1} \mathrm{c}$ (quintiles), insulin use, fasting before blood draw (less or more than $8 \mathrm{~h}$ ), smoking (current, past, never), BMI, physical activity (MET, quintiles), aspirin use and prevalence of CVD; $\mathrm{b}$ multivariate model + dietary

of 7\% (Fig. 1). The relationship between alcohol and inflammatory biomarkers persisted in both subgroups ( $p$ value for interaction $>0.05$ for all biomarkers). Repeating the analyses after stratifying the subjects according to obesity or smoking status revealed similar associations (data not shown). In stratified analysis, significant associations between alcohol intake and levels of fibrinogen, sTNFR-2 and sVCAM-1 were only observed among the 426 non-users of aspirin ( $p$ value for trend $<0.05$ ) and not among those who used aspirin on a regular basis (5 times per week or more). However, tests for interactions were not statistically significant.

In our cohort, 327 diabetics reported drinking wine, 233 drinking beer and 295 drinking spirits, all in dif- score (cereal fibres, polyunsaturated : saturated fat ratio, trans fats and glycaemic load); ${ }^{c}$ values only available for subjects who fasted before blood draw $(n=384)$

ferent combinations. In multivariate analysis including three types of alcoholic beverages simultaneously in the model, we examined the association between alcohol from wine, beer or spirits and plasma concentrations of HDL cholesterol, sTNFR-2, fibrinogen, sVCAM-1 and adiponectin (Table 4). In general, all three sources of alcohol were associated with increased levels of HDL cholesterol and adiponectin, and decreased levels of sTNFR-2, fibrinogen, and sVCAM-1. Although the strength of the association varied with the beverage type and biomarker studied, our results do not indicate that one source of alcohol is consistently superior to the others. 
a

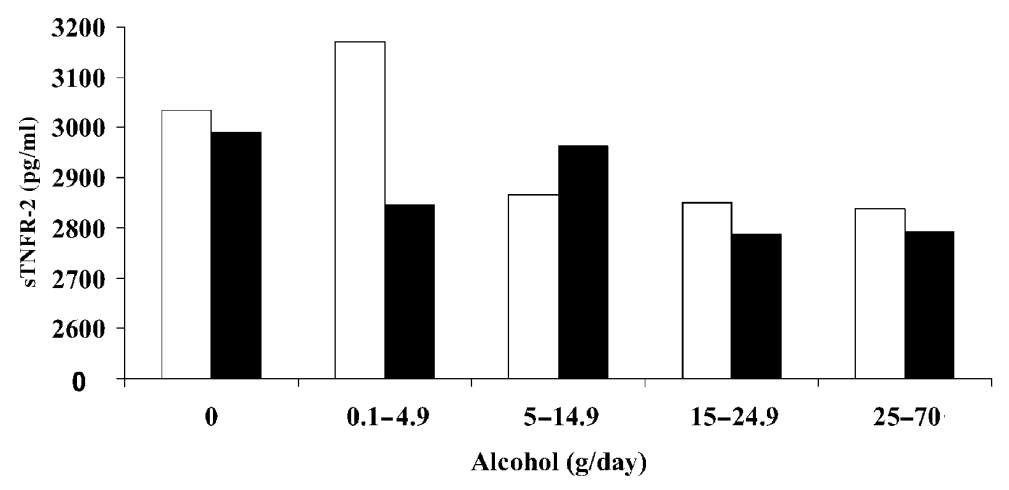

b

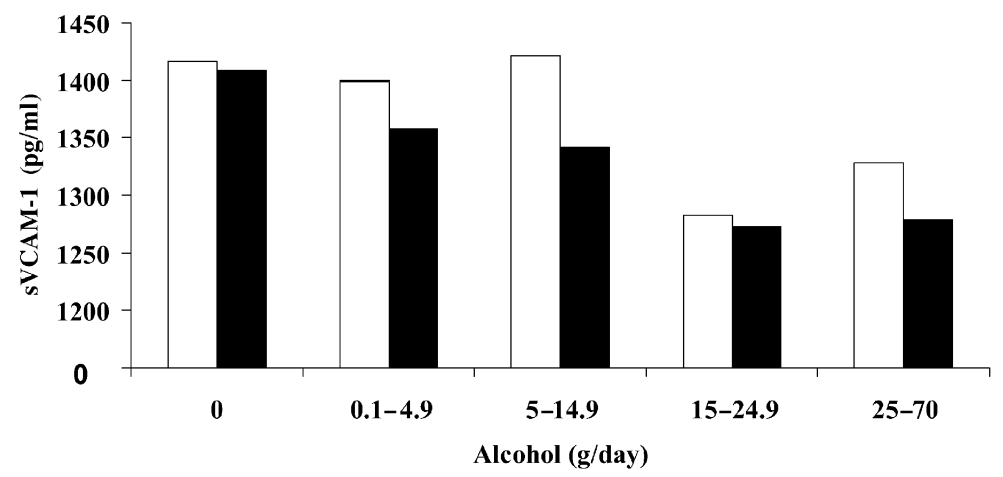

c

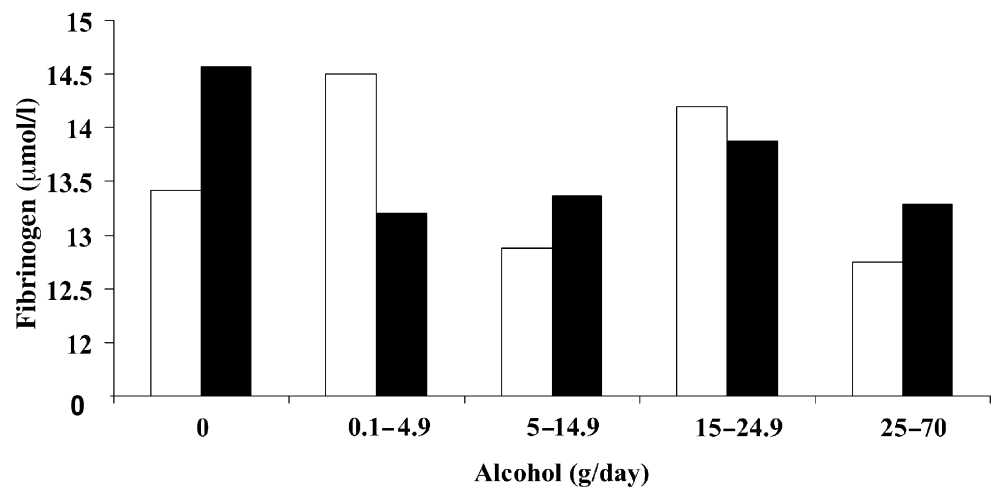

d

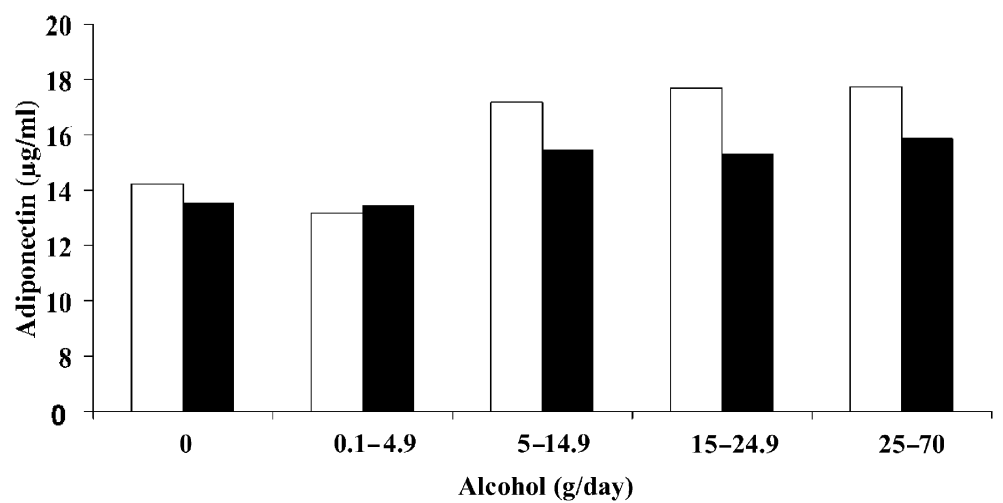


Table 4. Parameter estimates of selected plasma biomarkers related to an increment in alcohol intake of $12.5 \mathrm{~g} / \mathrm{day}$ according to alcohol source in 726 diabetic men

\begin{tabular}{lccr}
\hline Biomarker & \multicolumn{2}{l}{ Alcohol source } & \\
\cline { 2 - 4 } & Wine & Beer & Spirits \\
\hline HDL cholesterol $(\mathrm{mmol} / \mathrm{l})$ & $0.039(0.11)$ & $0.060(0.04)$ & $0.060(0.0001)$ \\
sTNFR-2 $(\mathrm{pg} / \mathrm{ml})$ & $-83.9(0.32)$ & $-152.6(0.11)$ & $-64.3(0.14)$ \\
Fibrinogen $(\mu \mathrm{mol} / \mathrm{l})$ & $0.005(0.99)$ & $-0.873(0.02)$ & $-0.268(0.12)$ \\
sVCAM-1 $(\mathrm{ng} / \mathrm{ml})$ & $-56.2(0.11)$ & $-1.0(0.98)$ & $-43.4(0.02)$ \\
Adiponectin $(\mu \mathrm{g} / \mathrm{ml})$ & $2.0(0.006)$ & $0.7(0.42)$ & $0.3(0.47)$
\end{tabular}

Values are shown as $\beta$ coefficients ( $p$ values) calculated using a multivariate model adjusted for age, $\mathrm{HbA}_{1} \mathrm{c}$ (quintiles), insulin use, fasting before blood draw (less or more than $8 \mathrm{~h}$ ),

\section{Discussion}

Moderate alcohol consumption was associated with reduced levels of TNF- $\alpha$, fibrinogen and SVCAM-1, and increased levels of adiponectin and HDL cholesterol in men with Type 2 diabetes. These observations remained significant after further adjustments for cardiovascular risk factors and glycaemic control. Moderate alcohol intake was not associated with triglycerides in this population.

Some of the limitations associated with the present study warrant consideration. Firstly, the cross-sectional design does not enable determination of causality. For example, alcohol intake was associated with lower levels of $\mathrm{HbA}_{1} \mathrm{c}$ and a lower proportion of insulin use. It is possible that diabetic men who had better glycaemic control were more likely to drink alcohol, in which case the observed associations would be more likely to be driven by the better health condition of these individuals. However, the associations persisted after adjustment for glycaemic control, and the benefits were similar in the two subgroups divided according to $\mathrm{HbA}_{1} \mathrm{c}$ levels. Secondly, alcohol intake assessment was estimated based on self-reports and may have been underestimated. However, the questionnaire has been previously validated and, as expected, alcohol intake was positively associated with HDL cholesterol levels in this study [26]. Thirdly, we could not distinguish between binge drinking and regular drinking and could not explore the effect of an alcohol intake of more than $70 \mathrm{~g} /$ day in our population. Finally, the HPFS does not represent a random sample of US

Fig. 1. Mean log-transformed values of the inflammatory biomarkers sTNFR-2 (a), sVCAM-1 (b), fibrinogen (c) and adiponectin (d) across categories of alcohol intake in diabetic men stratified according to $\mathrm{HbA}_{1} \mathrm{c}$ levels $\left(\mathrm{HbA}_{1} \mathrm{c}<7 \%, n=315\right.$, white bars; $\mathrm{HbA}_{1} \mathrm{c} \geq 7 \%, n=411$, black bars). Values were calculated using a multivariate model adjusted for age, insulin use, fasting before blood draw (less or more than $8 \mathrm{~h}$ ), smoking (current, past, never), BMI, physical activity (MET, quintiles), aspirin use and prevalence of CVD smoking (current, past, never) BMI, physical activity (MET, quintiles) aspirin use, prevalence of CVD and the other sources of alcohol

diabetic men; however, the relative socio-economic homogeneity of this population tends to reduce the impact of residual and unknown confounding factors.

Type 2 diabetes is associated with increased blood concentrations of inflammation markers $[1,2,3,4,6$, 8], which are known to predict the risk of future CVD [30]. A long-term cytokine-mediated acute-phase reaction could provide a mechanism for many of the abnormalities observed in Type 2 diabetes, including those in blood clotting, the reproductive system, metal ion metabolism, psychological behaviour and capillary permeability [2]. In addition to the assocition with HDL cholesterol, alcohol intake was also associated with markers of inflammation and endothelial dysfunction, such as TNF- $\alpha$, fibrinogen, sVCAM-1 and adiponectin. TNF- $\alpha$ is a cytokine that binds LDL cholesterol to endothelium and smooth muscle and increases the transcription of the gene encoding the LDL receptor. It modifies foam cell formation and several inflammatory products, contributing to the onset of atherosclerosis [31]. Fibrinogen, which is correlated with glycosylated haemoglobin and microalbuminuria [32], is known as an acute phase reactant. Increased levels of sVCAM-1, which mediates the adhesion and transmigration of leucocytes to the vascular endothelial wall, are associated with an increased risk of cardiovascular mortality in Type 2 diabetes [33]. Adiponectin, an adipocyte-derived protein, is strongly associated with HDL cholesterol [34]. Adiponectin gene location has been mapped to a diabetes-susceptibility locus [6], and the molecule has direct anti-inflammatory effects [7]. The positive association between alcohol and adiponectin may be mediated through HDL cholesterol, since adjustment for HDL cholesterol was shown to attenuate this relationship in the present study.

Although the reduction in each inflammatory marker is relatively small, the cumulative effects of alcohol on endothelial function may be substantial. In metabolic studies, the effects of alcohol on HDL cholesterol have also been reported to be relatively small; however, a large reduction in CHD risk has been observed 
with moderate alcohol intake [9]. This suggests that multiple mechanisms may account for the protective effects of alcohol. The observed effects of alcohol on HDL cholesterol in diabetic men in our study are comparable to those previously seen in the general population in metabolic studies [9]. It is difficult to compare the effects of alcohol on the multiple inflammatory markers assessed in our diabetic population with those in non-diabetic individuals because little data are available. However, in a previous study of healthy men [20], moderate alcohol consumption was associated with a modest reduction in $\alpha 1$-globulins and leucocyte levels.

CRP has emerged as a powerful marker of endothelial dysfunction and may have a pro-atherogenic effect on the vascular wall by inducing adhesion molecule expression in endothelial cells [35]. In non-diabetic individuals, moderate alcohol intake has been associated with decreased CRP levels [19, 20]. We observed a $12 \%$ reduction in CRP levels in subjects in the highest category of alcohol consumption (25-70 g/day), but this was not statistically significant. These results suggest that alcohol may have a smaller effect on CRP levels in diabetic subjects than in non-diabetic individuals. Furthermore, analyses performed following the stratification of patients according to levels of glycaemic control or use of insulin or aspirin did not reveal appreciable effect modification. However, since the median alcohol intake of the diabetic men ( $2.8 \mathrm{~g} /$ day $)$ was only half that of the healthy men in the HPFS ( $7 \mathrm{~g} /$ day), our ability to observe the effects of heavier alcohol consumption on CRP may be somewhat limited.

No consistent pattern emerged to suggest that one beverage is superior to the others. It appears that wine is more strongly associated with adiponectin than beer or spirits, but the associations with HDL cholesterol, fibrinogen and sTNFR-2 are stronger for beer than wine. In a previous epidemiological analysis of diabetic men in the HPFS, we found that different types of alcoholic beverages conferred similar benefits on the incidence of CHD [14].

The suggested benefits of alcohol consumption are limited to moderate levels of intake. The potential risks of alcohol in diabetic patients have recently been reviewed [15]. In diabetic patients, alcohol may induce hypoglycaemia, especially during prolonged fasting or in the presence of sulphonylurea medication [36]. However, the same study revealed no alteration of glucose homeostasis in diabetic patients who consumed a moderate amount of alcohol with meals. Although heavy drinking is associated with diabetic neuropathy and retinopathy, moderate alcohol intake poses little risk of these complications.

In conclusion, moderate alcohol consumption is associated with significantly lower levels of inflammatory and endothelial markers in diabetic men. These associations may partly explain the previously observed inverse association between alcohol and CHD in diabetic patients.
Acknowledgements. This study was supported by research grants (HL65582, HL35464, AA11181 and CA55075) from the National Institutes of Health. F.B. Hu is partly funded by an American Heart Association Established Investigator award. I. Shai is funded by the Fulbright Foundation, USA, and by the S. Daniel Abraham International Center for Health and Nutrition, Ben-Gurion University of the Negev (BeerSheva, Israel). The authors are not aware of any conflicts of interest in this study.

\section{References}

1. Pickup JC, Mattock MB, Chusney GD, Burt D (1997) NIDDM as a disease of the innate immune system: association of acute-phase reactants and interleukin- 6 with metabolic syndrome X. Diabetologia 40:1286-1292

2. Spranger J, Kroke A, Mohlig M et al. (2003) Inflammatory cytokines and the risk to develop type 2 diabetes: results of the prospective population-based European Prospective Investigation into Cancer and Nutrition (EPIC)-Potsdam Study. Diabetes 52:812-817

3. Morishita E, Asakura H, Jokaji H et al. (1996) Hypercoagulability and high lipoprotein(a) levels in patients with type II diabetes mellitus. Atherosclerosis 120:714

4. Leinonen E, Hurt-Camejo E, Wiklund O, Hulten LM, Hiukka A, Taskinen MR (2003) Insulin resistance and adiposity correlate with acute-phase reaction and soluble cell adhesion molecules in type 2 diabetes. Atherosclerosis 166:387-394

5. Festa A, D'Agostino R, Tracy RP, Haffner SM (2002) Elevated levels of acute-phase proteins and plasminogen activator inhitor- 1 predict the development of type 2 diabetes. The Insulin Resistance Atherosclerosis Study. Diabetes 51:1131-1137

6. Berg AH, Combs TP, Du X, Scherer PE (2001) The adipocyte-secreted protein Acrp30 enhances hepatic insulin action. Nat Med 7:947-953

7. Yokota T, Oritani K, Takahashi I et al. (2000) Adiponectin, a new member of the family of soluble defense collagens, negatively regulates the growth of myelomonocytic progenitors and the functions of macrophages. Blood 96:1723-1732

8. Spranger J, Kroke A, Mohlig M et al. (2003) Adiponectin and protection against type 2 diabetes mellitus. Lancet 361:226-228

9. Rimm EB, Williams P, Fosher K, Criqui M, Stampfer MJ (1999) Moderate alcohol intake and lower risk of coronary heart disease: meta-analysis of effects on lipids and haemostatic factors. BMJ 319:1523-1528

10. Carlsson S, Hammar N, Grill V, Kaprio J (2003) Alcohol consumption and the incidence of Type 2 diabetes: A 20-year follow-up of the Finnish twin cohort study. Diabetes Care 26:2785-2790

11. Valmadrid CT, Klein R, Moss SE, Klein BE, Cruickshanks KJ (1999) Alcohol intake and the risk of coronary heart disease mortality in persons with older-onset diabetes mellitus. JAMA 282:239-246

12. Solomon CG, Hu FB, Stampfer MJ et al. (2000) Moderate alcohol consumption and risk of coronary heart disease among women with type 2 diabetes mellitus. Circulation 102:494-499

13. Ajani UA, Gaziano JM, Lotufo PA et al. (2000) Alcohol consumption and risk of coronary heart disease by diabetes status. Circulation 102:500-505 
14. Tanasescu M, Hu FB, Willett WC, Stampfer MJ, Rimm EB (2001) Alcohol consumption and risk of coronary heart disease among men with type 2 diabetes mellitus. J Am Coll Cardiol 38:1836-1842

15. Tanasescu M, Hu FB (2001) Alcohol consumption and risk of coronary heart disease among individuals with type 2 diabetes. Curr Diab Rep 1:187-191

16. Clevidence BA, Reichman ME, Judd JT et al. (1995) Effects of alcohol consumption on lipoproteins of premenopausal women. A controlled diet study. Arterioscler Thromb Vasc Biol 15:179-184

17. Pellegrini N, Pareti FI, Stabile F, Brusamolino A, Simonetti $P$ (1996) Effects of moderate consumption of red wine on platelet aggregation and haemostatic variables in healthy volunteers. Eur J Clin Nutr 50:209-213

18. Kiechl S, Willeit J, Poewe W et al. (1996) Insulin sensitivity and regular alcohol consumption: large, prospective, cross sectional population study (Bruneck study). BMJ 313:1040-1044

19. Albert MA, Glynn RJ, Ridker PM (2003) Alcohol consumption and plasma concentration of C-reactive protein. Circulation 107:443-447

20. Imhof A, Froehlich M, Brenner H, Boeing H, Pepys MB, Koenig W (2001) Effect of alcohol consumption on systemic markers of inflammation. Lancet 357:763-767

21. Agewall S, Wright S, Doughty RN, Whalley GA, Duxbury M, Sharpe N (2000) Does a glass of red wine improve endothelial function? Eur Heart J 21:74-78

22. Teragawa H, Fukuda Y, Matsuda K et al. (2002) Effect of alcohol consumption on endothelial function in men with coronary artery disease. Atherosclerosis 165:145-152

23. National Diabetes Data Group (1979) Classification and diagnosis of diabetes mellitus and other categories of glucose intolerance. Diabetes 28:1039-1057

24. Hu FB, Leitzmann MF, Stampfer MJ, Colditz GA, Willett WC, Rimm EB (2001) Physical activity and television watching in relation to risk for type 2 diabetes mellitus in men. Arch Intern Med 161:1542-1548

25. Rimm EB, Giovannucci EL, Stampfer MJ, Colditz GA, Litin LB, Willett WC (1992) Reproducibility and validity of a expanded self-administered semiquantitative food frequency questionnaire among male health professionals. Am J Epidemiol 135:1114-1126

26. Giovannucci E, Colditz G, Stampfer MJ et al. (1991) The assessment of alcohol consumption by a simple selfadministered questionnaire. Am J Epidemiol 133:810817

27. Aderka D (1996) The potential biological and clinical significance of the soluble tumor necrosis factor receptors. Cytokine Growth Factor Rev 7:231-240

28. Hu FB, Manson JE, Stampfer MJ et al. (2001) Diet, lifestyle, and the risk of type 2 diabetes mellitus in women. N Engl J Med 345:790-797

29. U.S. Department of agriculture, Agriculture research service (1998) USDA Nutrient Database for Standard Reference, Release 12. U.S. Department of agriculture, Washington, D.C.

30. Ridker PM, Cushman M, Stampfer MJ, Tracy RP, Hennekens CH (1997) Inflammation, aspirin, and the risk of cardiovascular disease in apparently healthy men. N Engl J Med 336:973-979

31. Ross R (1999) Atherosclerosis: an inflammatory disease. New Engl J Med 340:115-126

32. Bruno G, Cavallo-Perin P, Bargero G, Borra M, D'Errico N, Pagano G (1996) Association of fibrinogen with glycemic control and albumin excretion rate in patients with non-insulin-dependent diabetes mellitus. Ann Intern Med 125:653-657

33. Jager A, van Hinsbergh VW, Kostense PJ et al. (2000) Increased levels of soluble vascular cell adhesion molecule 1 are associated with risk of cardiovascular mortality in type 2 diabetes: the Hoorn study. Diabetes 49:485-491

34. Matsubara M, Maruoka S, Katayose S (2002) Decreased plasma adiponectin concentrations in women with dyslipidemia. J Clin Endocrinol Metab 87:2764-2769

35. Pasceri V, Willerson JT, Yeh ET (2000) Direct proinflammatory effect of C-reactive protein on human endothelial cells. Circulation 102:2165-2168

36. Avogaro A, Tiengo A (1993) Alcohol, glucose metabolism and diabetes. Diabetes Metab Rev 9:129-146 